Certificate of Education, can be persuaded to interest themselves in, say, a group of common land invertebrates. He instanced earthworms, woodlice, grasshoppers and many others as examples of animals that are everywhere available, are still imperfectly studied, and of which the species native to Britain number less than fifty. These conditions provide a pupil with a manageable amount of material in which he may become a specialist. Mr. Savory believed that in this way a boy obtains more than fun from natural history; he can have a degree of satisfaction and even of pride in the work he is able to do. $\mathrm{He}$ is, moreover, taken away from the formal pages of the text-book, and makes his own acquaintance with the nature of zoology and with a zoologist's way of thinking. This is most apparent when, en route for scholarship honours, he enters a sixth form. "Scholars are bred in sixth forms", and despite the undeniable disadvantages of specializing, this early training may well supply one of the stepping-stones to success.

Speaking on the initial training of field workers, $\mathrm{Mr}$. F. J. Bingley (Flatford Mill Field Centre) said that this forms one of the most important functions of the field centres run by the Field Studies Council. There are now five such centres, each with qualified staff, laboratories and student accommodation, and with courses in all branches of field biology. As an example, he described how, at the Flatford Mill Field Centre at the head of the Stour estuary on the Essex-Suffolk border, courses for biology students are run at three academic levels, including general ecology courses for those with no previous experience ; specialized courses, for example, a freshwater biology course, where the students spend three or four days studying animal communities in different types of freshwater habitat followed possibly by a detailed survey of a stream and, on the last day, investigate some small problem on their own; and advanced courses for undergraduates and teachers, when the most modern field methods are taught by specialists. On all these courses attention is paid to fauna, flora and habitat, and emphasis is laid upon training in observation and the quantitative approach. Research workers also make use of the excellent facilities offered by the centres, and their results add materially to the teaching potential of the resident staff.

Dr. A. d'A. Bellairs (St. Mary's Hospital Medical School), speaking on the reptiles as a field of study, said that reptiles seldom figure prominently in the teaching of elementary zoology in Britain and, despite the fact that there are only six British species, much greater use might well be made of them. With their dry scaly skins and amniote eggs, the reptiles illustrate a more advanced stage in the colonization of the land than do any of our amphibians. Moreover, three British species are ovoviviparous, and can serve as a valuable source of living embryos. The slow-worm and the snakes are of further interest from a different point of view, for they are good examples of a particular type of extreme specialization, and provide an instructive contrast with the rather generalized animals which comprise most of the 'types' studied in courses of elementary zoology.

As a field of research, the reptiles present many problems in anatomy, physiology and behaviour. The recent observations of American herpetologists have shown the value of field studies, comparable with those which have been made for many years by ornithologists. Detailed and accurate observations on the territorial behaviour and the patterns of courtship in British reptiles would be of great interest ; so also would studies of their temperature tolerances, following the work of C. M. Bogert and others in the United States. Many anatomical problems, for example, the possible presence of vestigial limb-nerve plexuses in snakes, also seem well worth investigating, even by comparatively simple techniques.
H. G. Vevers

\title{
PHOTOBIOLOGICAL INVESTIGATIONS
}

\begin{abstract}
A MEETING of the Photobiology Group was held in Bedford College, London, on the afternoon of March 27. Three pepers were presented and afterwards discussed. Dr. C. A. Parker (Admiralty Materials Laboratory) described "Recent Advances in Spectrofluorimetry and Chemical Actinometry". The ferri-oxalate actinometer recently developed by Dr. Parker is several hundred times more sensitive than the uranyl oxalate one used until recently, as well as having other useful features, such as linearity to light intensity over a factor of $10^{8}$ and effectiveness from the far ultra-violet to the green. Its sensitivity permits its use for measuring spectral distributions, with narrow band pass filters, of daylight, discharge lamps, etc., and for calibrating spectrometer - photomultiplier set-ups, particularly in the ultra-violet region where other methods are very difficult. An instrument properly calibrated in this way can be used to measure the true shapes of fluorescence spectra. An even more valuable analytical method is to use a calibrated light-source spectrometer combination to excite fluorescence to determine a true 'action spectrum'; this should normally reproduce the absorption spectrum of the fluorescent substance even though the concentration is far too low for
\end{abstract}

ordinary absorption spectroscopy. Examples were shown of the use of this method for analysing rubber extracts.

Dr. R. S. Spencer (Food Investigation Laboratory, Hull) read a paper on "The Biology of Luminous Bacteria". He showed that luminous organisms are widely distributed within the animal kingdom but less widely so within the plant kingdom, only certain bacteria and fungi being luminous.

Luminous bacteria would appear to have one main habitat, the seas and the creatures living in the seas, and several minor ones, namely, fresh water and certain terrestrial animals on which they are parasitic. They are frequently present in enormous numbers on spoiled and spoiling fish, where they are responsible for the luminosity of such fish, a phenomenon noted long before the bacteria themselves were discovered.

Many different species of luminous bacteria from marine sources have been named but it is possible that a critical study will show the actual number of species present in this habitat to be quite low.

Fish, of diverse species, harbour luminous bacteria on their surface and in their intestines, frequently in very large numbers. Current work with fish caught around the British Isles and in the Arctic 
shows that only two species of luminous bacteria are present in significant amounts.

The physiology and biochemistry of the more common and well-studied species from marine sources show them to be well adapted to their environment. All will grow in the absence of oxygen and will luminesce at low oxygen concentrations. Many will grow and luminesce at temperatures around $0^{\circ} \mathrm{C}$. Some, however, have relatively complex nutritional requirements in artificial culture, a possible indication that they are not free-living in the seas. As some species tolerate relatively high concentrations of bile salts, it is possible that their natural habitat is the intestines of fish.

Mr. E. S. Trickett (National Institute of Agricultural Engineering, Silsoe) described "Problems of
Radiation Measurement in Relation to Environmental Control". The great difficulties of measuring the distribution of light and heat in glass-houses were pointed out. The wave-length range to be considered reaches from 3,000 to $30,000 \mathrm{~A}$., and well beyond if thermal radiation has to be taken into account. The combination of spatial, temporal, and wave-length factors makes a very formidable problem. When to this is added the need for cheap detectors (existing ones cost several hundred pounds each), because monitoring must be carried out simultaneously at many different points, it is not surprising that research workers are still compelled to conduct growth experiments in glass-houses under very primitive forms of light control.

E. J. BoweN

\section{DEVELOPMENT OF ARCHITECTURAL SCIENCE}

A PUBLICATION* of the University of Sydney Extension Board contains twelve lectures and records of discussions, which were held in the autumn of 1956, on subjects under the general heading of "Structure and Architecture". Section $A$ contains four lectures on mechanics ; Section $B$, four lectures on resthetics; and Section $C$, four lectures on construction. The purpose of the lectures is stated to be "to supplement the postgraduate work of architects and architectural assistants and to assist in maintaining interest in the study of the development of structure as related to architecture".

In the first lecture on mechanics, "The Traditional Architectural Forms and the Beginning of the Era of Scientific Structural Design", H. J. Cowan traces the development of the structural form of large buildings through the ages and suggests that its pattern is due to advances in materials and techniques as well as in theory of structures. An interesting account of the main stages in the earlier developments in the latter is included. The next lecture considers "Onedimensional Structures-the Invention of Steel and Reinforced Concrete Construction". It deals with the influence on structural design of the invention of high-strength materials such as steel and reinforced concrete on one hand, and the development of reliable theories for predicting the strength of structural members, on the other. The main result of these advances during the earlier part of the nineteenth century was an increase in the scale of the beam and column type of construction. The third lecture, "Two-dimensional Structures", is mainly concerned with the development of the theory of rigid two-dimensional frames since the middle of the nineteenth century, as a result, initially, of the work of Culmann, Ritter, Maxwell, Mohr and others and, more recently, of the powerful method of moment distribution due to Hardy Cross. The final lecture on mechanics by Prof. Cowan, "The Revival of Curved Roofs and of Three-dimensional Structures", deals with the recent development of integral three-dimensional structures of the shell type, largely as a result of advances in concrete construction techniques. The theory of arch and shell behaviour is outlined, together with the possibility of using

* Architectural Science No. 2: Proceedings of the Symposium on Structure and Architecture. Edited by Prof. Henry J. Cowan. Pp. xii +95-200. (Sydney: Sydney University Extenston Borrd, 1957. Copies obtainable from Academic Press, Pty., Ltd.) 218. experimental (scale model) techniques to circumvent mathematical analysis.

"An Historical Survey of the Influence of Structural Development on Contemporary Architecture" is the title of the first of the lectures on æesthetics. The lecturer, A. N. Baldwinson, suggests that the emotional neutrality of the architecture of many works of the nineteenth century reflects the cessation of the inclusion of the activities of the structural engineer in those of the architect, owing to the increasing complexity of the structural aspect due to new developments. It is noted that nowadays engineers and architects are co-operating, to the advantage of the resthetic aspect. The principal events since 1735 which have influenced architectural development are noted in chronological order in an appendix. The subject of the lecture of F. E. A. Towndrow is "The Theory of Architectural Design in relation to Structures". Some contemporary theories in architectural rsthetics are described and the relevance of resthetic theories to the work of the engineer is discussed with reference to the opinions of Arup and Nervi. The latter is quoted as saying that æsthetic considerations are fundamental. The place of resthetics in all creative work is outlined, and the training of architects and structural engineers in different ways in separate schools is deplored. The third lecture on æesthetics, "A Painter Looks at Architectural Structure", is by Lloyd Rees and deals with the purely visual aspect. For example, the relationship of buildings to their surroundings is discussed, with emphasis on maintaining local character. It is suggested that one of the most inspiring features of modern structural technique is the covering of large areas without intermediate support. In the final lecture on æsthetics, "The Art of Space", R. B. Grounds asserts that the purpose of architecture is expression, the medium is spece and the tool is building. Examples of the concept of space in the architecture of old and new buildings are given and it is suggested that greatness in architecture is only incidentally related to the technological methods employed.

The subject of the first lecture under the general heading of construction is "The Economics of Multistory Buildings". In it, F. Woolard examines the factors which influence the cost of multi-story buildings and separates them into items of capital cost, running cost and maintenance cost, noting that 